\title{
Alkukukintakauden hyönteispölyttäjät tärkeitä tattarin pähkyläsadolle
}

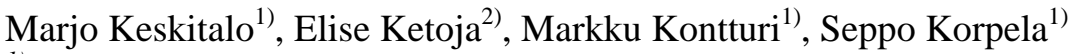 \\ ${ }^{1)}$ MTT Kasvintuotannon tutkimus, 31600 Jokioinen, etunimi.sukunimi@mtt.fi \\ ${ }^{2)}$ MTT Palveluyksikkö, 31600 Jokioinen, Elise.Ketoja@mtt.fi
}

\section{Tiivistelmä}

Tattarin (Fagopyrum esculentum) viljelyä varjostavat satovaihtelut, joiden oletetaan johtuvan ainakin osaksi kukkien epätäydellisestä pölyttymisestä. Ristipölytteisenä kasvina siitepölyn kulkeutumiseksi emikukkaan tarvitaankin lukuisia yhteensopivia tapahtumia. MTT:ssä vuosina 2003 2007 tehdyn Terveyttä tattarista - hankkeen yhtenä tavoitteena oli tuottaa tietoa siitä, mitä lentäviä hyönteisiä tattarilla tavataan ja miten niiden runsauden vaihtelu vaikuttaa pähkyläsatoon.

Vuosina 2005 ja 2006 Jokioisilla tehtiin kenttäkokeita, joihin asetettiin tuulen ja sateen läpäiseviä mutta lentävien hyönteisten kulun estäviä telttoja juuri ennen kukinnan alkua. Ensimmäisenä vuonna peitettiin kaksi kolmasosaa kentän ruuduista teltoilla ja puoleen näistä asetettiin mehiläispesä sisälle. Yksi kolmasosa kentän koeruuduista jätettiin avoimeksi, jolloin hyönteisillä oli niihin vapaa pääsy. Toisena vuotena koejäseninä olivat teltalla peitetty ja avoin ruutu. Katteet saivat olla paikoillaan syyskuussa tehtyyn korjuuseen saakka. Kentän reunoille asetettiin mehiläispesiä. Pölyttävien hyönteisten esiintymistä avoimella kentällä seurattiin koko kukintakauden ajan.

Avoimen tattarikasvuston kukissa havaittiin pistiäisiä kuten mehiläisiä (Hymenoptera Apis mellifera), kimalaisia (Hymenoptera Bombus ssp.) ja ampiaisia (Hymenoptera Vespidae) sekä erilaisia kaksisiipisiä kuten kukkakärpäsiä (Diptera Syrphidae ssp.). Pölyttäjien esiintyminen vaihteli kukintavaiheen aikana. Myös vuosien välillä havaittiin eroja. Tattarin pähkyläsato muodostuu suurelta osin niistä kukista, jotka pölyttyvät kukinnan alkupuolella. Siksi sadon kannalta merkityksellisimpiä ovat todennäköisesti juuri mehiläiset ja kaksisiipiset, joita esiintyy runsaana tattarin alkukukinnan aikana heinäkuussa. Tutkimuksessa tattarin pähkyläsato oli $35 \mathrm{~g} / \mathrm{m}^{2}$ (35 \%) suurempi silloin kun kasvustossa esiintyi runsaasti pölyttäjiä verrattuna tilanteeseen, kun lentäviä hyönteisiä ei päästetty kasvustoon. Kerranteiden välisestä vaihtelusta johtuen satoero ei kuitenkaan ollut tilastollisesti merkitsevä ja siksi tulokset eivät ole yleistettävissä. Jatkotutkimuksissa tulisikin kiinnittää huomiota kasvuston peittäviin katemateriaaleihin sekä toistojen määrään.

Tutkimusvuosina 2005 ja 2006 tattarin sadot erosivat selvästi toisistaan, vaikka kasvustot kehittyivät molempina vuosina hyvin. Sato oli vuonna 2006 keskimäärin 72 g/m² (65 \%) suurempi kuin 2005. Samantapaiset satovaihtelut ovat tyypillisiä myös käytännössä. Hyvänä satovuonna 2006 mehiläisiä olikin alkukukintavaiheessa vähintään kaksinkertainen määrä vuotta aikaisempaan tilanteeseen. Sen lisäksi sekä mehiläiset että kaksisiipiset esiintyivät runsaimmillaan samaan aikaan eli heinä-elokuun vaihteessa, kun vuotta aikaisemmin hyönteiset esiintyivät hyvin eri aikaan. Pölyttäjien vähyys alkukukintakaudella selittäneekin ainakin osan vuoden 2005 huonosta tattarisadosta.

\section{Asiasanat}

Tattari, Fagopyrum esculentum, pölyttäjät, pistiäiset, kaksisiipiset, sato 


\section{Johdanto}

Tattarin (Fagopyrum esculentum) kukinta alkaa noin 5-6 viikon kuluttua kylvöstä, mutta kasvullinen vaihe jatkuu ainakin Suomessa elokuulle saakka. Uusia kukkaterttuja muodostuu kehittyviin lehtihankoihin vielä loppukesällä, sillä tattarin kukinta on päätteetön. Tattari tuottaakin ylimäärin kukkia, joista vain osa kehittyy siemeneksi. Kasvihuonekokeessa, jossa kukkien pölyttymistä autettiin käsin, vain $20 \%$ tuotti siementä (Taylor \& Obendorf 2001).

Satoa tuottaakseen tattari vaatii ristipölytyksen ja kukan morfologisen rakenteen takia itsepölytys onkin harvinaista. Kukissa heteet ja emi ovat eri tasoissa ja kukkia on myös kahdenlaisia. 'Pin'-tyyppin kukissa emi on heteitä pitempi ja 'trum'-tyyppisissä heteet ovat puolestaan emiä pitempiä (Marshall \& Pomeranz 1982). Yhdessä tattarikasvissa voi esiintyä vain jompaakumpaa kukkatyyppiä, jotka tuottavat erikokoista siitepölyä ja myös mettä eri tavalla (Cawoy ym. 2006a).

Tattarin satovaihtelut voivat olla suuria sillä hyviltäkin näyttävien kasvustojen lopulliset hehtaarisadot vaihtelevat 500 - 2000 kg välillä. Pähkyläsatoon on mainittu vaikuttavan muun muassa kuivuus juuri ensimmäisten kukkien kehittymistä (Cawoy ym. 2006b), pölyttäjien puute (Goodman ym. 2001), siitepölyn huono hedelmöityskyky (Taylor \& Obendorf 2001), siitepölyn niukkuus (Björkman 1995) sekä epäkypsien siementen variseminen (Halbrecq ym. 2005).

Tattarin siitepölyä levittävät etenkin hyönteiset mutta myös tuuli. Tutkimuksen mukaan alle 2\% risteytyksistä tapahtuisi tuulen välityksellä (Michiyama ym. 2007). Yli $60 \%$ risteytymistä on todettu tapahtuvan 0 - 3 metrin etäisyydellä, mutta vielä 100 metrin etäisyydellä noin $1 \%$ tattaripähkylöistä todettiin ristipölyttyneen lähtömateriaalin kanssa (Adhikari \& Campbell 1998). Ulkomailla tehtyjen tutkimusten mukaan tattarin pölyttäjissä on ollut jonkin verran vaihtelua eikä tarkkaa tietoa ole eri pölyttäjien merkityksestä satoon (Michiyama ym. 2007, Goodman ym. 2001, Ogasahara ym. 1995).

Tattari on ympäristön kannalta mielenkiintoinen viljelykasvi ja pähkylän koostumus sallisi kasvia käytettävän nykyistä paljon laajemmin ja monipuolisemmin. Suuret satovaihtelut kuitenkin rajoittavat viljelyinnostusta. MTT:ssä vuosina 2003 - 2007 tehdyn Terveyttä tattarista -hankkeen yhtenä tavoitteena olikin tuottaa tietoa siitä, mitä lentäviä hyönteisiä tattarin kukissa esiintyy ja minkälainen merkitys niillä on satoon.

\section{Aineisto ja menetelmät}

Vuosina 2005 ja 2006 Jokioisilla tehdyt kenttäkokeet kylvettiin kesäkuun alussa 'Ilkka'paikalliskantaa käyttäen. Siemenmääränä käytettiin 160 itävää siementä/ $\mathrm{m}^{2}$ ja lannoituksena $200 \mathrm{~kg} / \mathrm{ha}$ Kevätviljan Y3:sta (20:3:8). Juuri ennen heinäkuun puolivälissä alkanutta kukintaa asennettiin koeruutuihin tuulen ja sateen läpäiseviä telttoja, jotka kuitenkin estivät lentävien hyönteisten kulun. Ensimmäisenä vuonna peitettiin kaksi kolmasosaa koko kentän koeruuduista teltoilla ja puoleen näistä asetettiin mehiläispesä sisälle. Yksi kolmasosa kentän koeruuduista jätettiin avoimeksi ja niihin hyönteisillä oli vapaa pääsy. Toisena vuotena puolet kentän koeruuduista peitettiin teltoilla ja puolet jätettiin avoimeksi. Testattavana oli kolme erilaista telttatyyppiä. Katteet saivat olla paikoillaan syyskuussa tehtyyn korjuuseen saakka. Kentän reunoille asetettiin mehiläispesiä. Toistoja molempina vuosina oli tavallista enemmän eli seitsemän.

Pölyttävien hyönteisten esiintymistä avoimella kentällä seurattiin kukinnan aikana kaksi kolme kertaa viikossa aamupäivisin kaista- ja ruutulaskentojen avulla. Kaistalaskennat tehtiin siten, että kävelyvauhtia edeten laskettiin mehiläiset (Apis mellifera) ja kimalaiset (Bombus ssp.) kentän reunalta ja metrin levyiseltä ja 50 metrin pituiselta kaistalta. Ruutulaskennoissa tarkkailtiin $0,25 \mathrm{~m}^{2}$ :n suuruista merkittyä neliötä kolmen minuutin ajan. Sadon määritystä varten korjattiin syyskuun puolessa välissä avoimista ja teltalla peitetyistä koeruuduista yhden neliön suuruiset alat. 


\section{Tulokset ja tulosten tarkastelu}

\section{Pölyttäjien esiintyminen}

Avoimen, ilman telttaa olevan tattarikasvuston kukissa havaittiin kaksisiipisiä kuten kukkakärpäsiä (Diptera Syrphidae ssp.) sekä pistiäisiä kuten ampiaisia (Hymenoptera Vespidae), kimalaisia (Hymenoptera Bombus ssp.) mehiläisiä (Hymenoptera Apis mellifera). Mehiläisiä havaittiin erityisen runsaana heinäkuun 20 - 31 päivien välisenä aikana, jolloin niitä saattoi olla 10 - 20 yksilöä havaintoruutua $\left(0,25 \mathrm{~m}^{2}\right)$ ja tarkkailuaikaa $(3 \mathrm{~min})$ kohti. Sen jälkeen niiden määrä väheni. Kaksisiipisiä kuten kukkakärpäsiä havaittiin koko kukintakaudella aina syyskuulle asti, mutta runsaimmillaan elokuun alussa. Parhaimmillaan niitä oli 15 - 25 yksilöä havaintoruutua $\left(0,25 \mathrm{~m}^{2}\right)$ ja tarkkailuaikaa (3 min) kohti. Kimalaisia esiintyi heinäkuussa runsaimmillaan 1-2 yksilöä ja ampiaisia vieläkin vähemmän havaintoruutua $\left(0,25 \mathrm{~m}^{2}\right)$ ja tarkkailuaikaa $(3 \mathrm{~min})$ kohti. Tulokset ovat samansuuntaisia ulkomailla tehtyjen kokeiden kanssa. USA:ssa ja Australiassa mehiläiset (Apis mellifera) (Goodman ym. 2001, Björkman \& Pearson 1995) käsittivät 80 - 95 \% kaikista hyönteisistä. Japanissa kukkakärpäset (Syrphidae ssp.) olivat yleisimpiä vierailijoita kukissa kun taas mehiläisiä havaittiin vain kukintajakson keskivaiheilla (Ogasahara 1995). Belgiassa puolestaan mehiläisiä esiintyi alkukukintavaiheessa ja kaksisiipisiä myöhemmin. Kaksisiipisten aktiivisuus ja runsas esiintyminen epäiltiin viittaavaan jonkinlaiseen osallistumiseen myös itse pölytykseen (Jacquemart ym. 2007). Mehiläiset ja kaksisiipiset mukaan lukien tattarin kukista tunnistettiin yhteensä 49 hyönteislajia (Jacquemart ym. 2007). Japanissa myös kävelevien hyönteisten kuten muurahaisten todettiin olevan tärkeitä pölyttäjiä (Michiyama ym. 2007).

MTT:n tutkimuksessa pölyttäjien määrissä havaittiin eroja vuosien välillä. Kaistalaskennoissa, joissa havainnot tehtiin suuremmalta alalta (50x1 m) mutta vain mehiläisistä ja kimalaisista, havaittiin että mehiläisten osuus oli 77 - $100 \%$. Mikäli kaksisiipiset olisi laskettu, olisi mehiläisten osuus ollut pienempi. Vuonna 2005 mehiläisiä tavattiin heinäkuussa (12.7.-29.7.2005) keskimäärin 28 yksilöä (vaihtelu 4,5-92) ja vuonna 2006 (11.7-30.7.2006) keskimäärin 55 yksilöä (vaihtelu 10-91) 50 metrin kaistalla havaintokertaa kohti. Myös ruutulaskennoissa ero näkyi. Sen sijaan kaksisiipisiä oli vuonna 2005 (1.8.-28.8.2005) keskimäärin 7,6 (vaihtelu 0,6-19) ja vuonna 2006 (2.8.-25.8.2005) keskimäärin 1,5 (vaihtelu 0,3-2,7) yksilöä havaintoruutua $\left(0,25 \mathrm{~m}^{2}\right)$ ja -aikaa (3 min) kohti. Kaiken kaikkiaan pölyttäjiä ja erityisesti kaksisiipisiä esiintyi vuonna 2005 syyskuun alkuun asti kun vuonna 2006 niitä ei juurikaan havaittu enää elokuun toisen viikon jälkeen.

\section{Pölyttäjien vaikutus pähkyläsatoon}

Vuonna 2005 verrattiin pölyttäjille avointen, pölyttäjiltä estettyjen (katettu teltoilla) sekä ulkopuolisilta pölyttäjiltä estettyjen (katettu teltoilla) ja mehiläispesän sisältäneiden ruutujen satoja. Suurin keskimääräinen pähkyläsato $\left(134 \mathrm{~g} / \mathrm{m}^{2}\right)$ saatiin teltoilla katetuista ja mehiläisiä sisältäneistä ruuduista. Keskisadot avoimista ja teltalla suljetuista ruuduista olivat 111 ja $99 \mathrm{~g} / \mathrm{m}^{2}$. Avoimet ruudut tuottivat siten noin $23 \mathrm{~g} / \mathrm{m}^{2}$ (17 \%) pienemmän sadon kuin ruudut, joilla oli mehiläisiä sisältävä teltta. Ero oli kuitenkin tilastollisen merkitsevyyden rajoilla $(\mathrm{p}=0.05)$ sadoissa esiintyneen suuren vaihtelun takia. Avoimen koejäsenen sato oli puolestaan noin $12 \mathrm{~g} / \mathrm{m}^{2}$ (11\%) suurempi kuin lentäviltä pölyttäjiltä suljetun teltan, mutta ero ei ollut tilastollisesti merkitsevä ( $\mathrm{p}=0.41)$.

Vuonna 2006 verrattiin pölyttäjille avoimen ja pölyttäjiltä suljetun koejäsenten välisiä eroja kolmen erilaisen telttatyypin avulla. Avointen ruutujen keskisato oli teltoista kahteen, erilaisesta kankaasta valmistettuun verrattuna 43 ja $70 \mathrm{~g} / \mathrm{m}^{2}$ (30 ja 62\%) suurempi. Erot olivat tilastollisesti merkitseviä $(\mathrm{p}<0.001)$. Sen sijaan pienisilmäisestä verkkokankaasta tehdyn katteen alla sato oli avointa ruutua $23 \mathrm{~g} / \mathrm{m}^{2}$ eli $13 \%$ suurempi ( $\mathrm{p}=0.01$ ). Keskimäärin sadot olivat avoimissa ruuduissa 183 $\mathrm{g} / \mathrm{m}^{2}$, teltoilla katetuissa ruuduissa 114 ja $144 \mathrm{~g} / \mathrm{m}^{2}$ ja verkkokankaalla katetuissa ruuduissa $203 \mathrm{~g} / \mathrm{m}^{2}$.

Ruutujen katemateriaali vaikutti siten tattarin kasvuun ja siksi vertailu pelkästään avointen ja teltalla suljettujen ruutujen välillä ei anna täysin oikeaa kuvaa pölyttäjien vaikutuksesta pähkyläsatoon. Vuonna 2005 kokeessa oli mukana teltalla katettuja ruutuja, joista puolessa oli mehiläispesä sisällä. Silloin mehiläisiä sisältänyt teltalla katettu ruutu tuotti keskimäärin 35 g/m² (35 \%) enemmän pähkyläsatoa kuin teltta ilman mehiläisiä. Ero ei kuitenkaan ollut tilastollisesti merkitsevä sadoissa esiintyneen suuren vaihtelun takia.

MTT:ssä saadut tulokset pölyttäjien merkityksestä tattarin sadolle ovat samansuuntaisia ulkomaisten tulosten kanssa. Australiassa tehdyssä kokeessa tattarin kukintakausi oli jaettu neljään 
jaksoon (jaksot 1-4) ja mehiläisillä oli vapaa pääsy kasvustoon jakso kerrallaan. Kun mehiläisten pääsy oli kokonaan estetty, oli sato noin 50 \% pienempi avonaiseen verrattuna. Suurin merkitys pölyttäjillä oli kukinnan alkuvaiheessa, sillä vain jaksolla 2. avoimena ollut koejäsen tuotti koko kukintakauden avoimena olleeseen ruutuun verrattuna yhtä suuren sadon (Goodman ym. 2001). EteläAmerikassa tehdyssä kokeessa mehiläisten pääsyn estäminen kukintavaiheessa olevaan tattarikasvustoon tuotti noin 30 \% alemman sadon avonaiseen verrattuna (de Ugarte Serra 1991). Suomessa on tutkittu pölyttäjien merkitystä rypsillä (Brassica campestris) (Korpela 1988) ja härkäpavulla (Vicia faba) (Varis \& Brax 1990), joiden sadot jäivät 28 - 75 \% (Korpela 1988) ja 15 - 19 \% (Varis \& Brax 1990) matalimmiksi ilman lentävien hyönteisten pääsyä kasvustoon. Härkäpavulla ja rehuvuohenherneellä (Galega orientalis) $44 \%$ kukissa kävijöistä oli mehiläisiä ja loput 56 \% kimalaisia. Rypsillä mehiläisten osuus oli 60 - 97 \% (Korpela 1988, Varis 1995) ja kimalaisten 2 - 40 \% (Korpela 1988) pölyttäjistä.

\section{Johtopäätökset}

Tattarin pähkyläsato muodostuu suurelta osin niistä kukista, jotka pölyttyvät kukinnan alkupuolella. Siksi sadon kannalta merkityksellisimpiä ovat todennäköisesti juuri mehiläiset ja kaksisiipiset, joita esiintyy runsaana heinäkuun lopulla ja elokuun alussa. Muita tattarin kukkien kävijöitä ovat kimalaiset ja ampiaiset. Tutkimuksessa tattarin pähkyläsato oli 35 g/m² (35 \%) suurempi, kun kasvustossa oli runsaasti pölyttäjiä verrattuna oloihin, joissa pölyttäjiä ei ollut. Kerranteiden välisestä vaihtelusta johtuen satoero ei kuitenkaan ollut tilastollisesti merkitsevä ja siksi tulokset eivät ole yleistettävissä. Jatkotutkimuksissa tulisikin kiinnittää huomiota kasvuston peittäviin katemateriaaleihin sekä toistojen määrään.

Tutkimusvuosina 2005 ja 2006 tattarin sadot erosivat selvästi toisistaan, vaikka kasvustot kehittyivät molempina vuosina hyvin. Sato oli vuonna 2006 keskimäärin 72 g/m² (65 \%) suurempi kuin 2005. Samantapaiset satovaihtelut ovat tyypillisiä myös käytännössä. Hyvänä satovuonna 2006 mehiläisiä olikin alkukukintavaiheessa vähintään kaksinkertainen määrä vuotta aikaisempaan tilanteeseen. Sen lisäksi sekä mehiläiset että kaksisiipiset esiintyivät runsaimmillaan samaan aikaan eli heinä-elokuun vaihteessa, kun vuotta aikaisemmin nämä esiintyivät pääasiallisesti eri aikoina. Pölyttäjien vähyys alkukukintakaudella selittäneekin ainakin osan vuoden 2005 huonosta tattarisadosta.

\section{Kirjallisuus}

Adhikari, K.N. \& Campbell, C.G. 1998. Natural outcrossing in common buckwheat. Euphytica 102: 233-237. Björkman, T. 1995. Gametophyte selection through pollen competition in buckwheat. In: Proceedings of the VI international symposium of buckwheat, Current advances in buckwheat research, Shinshu University, Shinshu, Japan, pp 443-451.

Björkman, T. \& Pearson, K. 1995. The inefficiency of honeybees in the pollination of buckwheat. In: Proceedings of the VI international symposium of buckwheat, Current advances in buckwheat research, Shinshu University, Shinshu, Japan, pp 453 - 462.

Cawoy, V., Deblauwe, V., Halbrecq, B., Ledent, J.F., Kinet, J.M. \& Jacquemart, A.L. 2006a. Morp differences and honeybee morph preference in the distylous species Fagopyrum esculentum Moench. International Journal of Plant Sciences 167: 853-861.

Cawoy, V., Lutts, S. \& Kinet, J.-M. 2006b. Osmotic stress at seedling stage impairs reproductive development in buckwheat (Fagopyrum esculentum). Physiologia Plantarum 128: 689-700.

Goodman, R., Hepworth, G., Kaczynski, P., McKee, B., Clarke, S. \& Bluett, C. 2001. Honeybee pollination of buckwheat (Fagopyrum esculentum Moench) cv. Manor. Australian Journal of Experimental Agriculture 41: $1217-1221$.

Halbrecq, B., Romedenne, P. \& Ledent, J.F. 2005. Evolution of flowering, ripening and seed set in buckwheat (Fagopyrum esculentum Moench): quantitative analysis. Europ. J. Agronomy 23: 209-224.

Korpela, S. 1988. The influence of honeybee pollination on turnip rape (Brassica campestris) yield and yield components. Annales Agriculturae Fenniae 27: 295-303.

Marshall, H.G., \& Pomeranz, Y. 1982. Buckwheat: description, breeding, production and utilization. In: Advances in Cereal Science and Technology 5: 157-210. 
Michiyama, H., Urushibata, M., Otani, I., Sakamoto, H., Yamagishi, K. \& Hirano, T. 2007. Effect of interruption of pollination by walking of flying insects on seed-set in buckwheat. In: Proceedings of the $10^{\text {th }}$ international symposium on buckwheat, Northwest A \& F University (NWAFU), Yangling, Shaanxi, China, pp 142 - 145.

Ogasahara, S., Kaji, C., Hagiwara, M. \& Matano, T. 1995. Pollination of common buckwheat (Fagopyrum esculentum Moench) as influenced by meteorological conditions. In: Proceedings of the VI international symposium of buckwheat, Current advances in buckwheat research, Shinshu University, Shinshu, Japan, pp 475481.

Taylor, D.P. \& Obendorf, R.L. 2001. Quantitative assessment of some factors limiting seed set in buckwheat. Crop Sci. 41: 1792-1799.

de Ugarte Serra, P.M. 1991. Pollinating agents and buckwheat yield (Fagopyrum esculentum), Tesis de Grado de Agronomia, Universidad Austral de Chile, Valdivia, 123 p.

Varis, A.-L. 1995. Abundance, species composition and daily pattern of bees visiting field bean, goat's rue and turnip rape in southern Finland. Agricultural Science in Finland 4: 473-478.

Varis, A.-L. \& Brax, R. 1990. Effect of bee pollination on yield and yield components of field bean (Vicia faba L.). Journal of Agricultural Science in Finland 62: 45-49. 